\title{
Social science and forestry curricula: Some survey results
}

\author{
by David B. Tindall ${ }^{1}$
}

In this article, findings from a study of a forestry curriculum are used to identify current gaps and potential avenues of pedagogical contributions pertaining to social science content. In setting a context for this analysis a brief review of the potential contributions of social science to forestry, and a description of current social science research on forestry in B.C. and the surrounding region is provided. Survey results from: 1) stakeholders in forestry, 2) forestry undergraduate students, and 3) forestry faculty all point to the need for incorporating more social science content into forestry curricula. These survey results dovetail with observations about the need for more social science research on forestry topics.

Key words: social science, forestry curricula, intergroup differences, social survey research

Dans cet article, les résultats d'une étude d'un programme de foresterie sont utilisés pour identifier les lacunes actuelles et les directions possibles offertes par les contributions pédagogiques des sciences sociales en foresterie, et une description de la recherche actuelle en sciences sociales sur la foresterie en Colombie-Britannique et les régions immédiates est présentée. Les résultats du sondage provenant : 1) des intervenants en foresterie, 2) des étudiants au baccalauréat en foresterie, et 3) du personnel enseignant en foresterie indiquent tous la nécessité d'incorporer plus de sciences sociales dans les programmes de foresterie. Ces résultats du sondage rejoignent les observations faites sur la nécessité d'avoir plus de recherches en sciences sociales dans le cas des sujets touchant la foresterie.

Mots-clés : sciences sociales, programmes de foresterie, différences entre les groupes, recherche sur les sondages sociaux

\section{Introduction: Social Science and Forestry}

Until recently, beyond the discipline of economics, social science appeared to have little relevance for those in Canada concerned with forestry issues. ${ }^{2}$ Patricia Marchak's groundbreaking book, Green Gold, published in 1983 helped to $\exists$ forge some connections between sociology and forestry. In I recent years scholars concerned with forestry issues have become incering increas in science has to offer. This is partly due to a lack of confidence that has developed amongst substantial segments of the public in the "industrial/economic optimization paradigm" of forestry that has dominated for most of the past century. Current efforts to achieve a more "holistic forestry paradigm" have provided a window of opportunity for sociologists (and social scientists more generally) to build upon the contributions of Marchak and a few others.

In this article I will report on the results of an opinion survey about the relative importance of social science knowledge to the graduating professional forester. In order to provide a context for this I will briefly review the work of some other scholars on the potential and current contributions of social science to forestry.

\footnotetext{
${ }^{1}$ Department of Forest Resources Management, University of British Columbia, 2nd Floor, Forest Sciences Centre, 2045 - 2424 Main Mall, Vancouver, B.C. V6T 1Z4. Email: tindall@interchange.ubc.ca

${ }^{2}$ One of the anonymous referees brought to my attention that B.E. Fernow writing in the early part of the twentieth century expressed the opinion that social issues were relevant to forestry. However, his view was that such issues were a matter of common sense rather than of scientific investigation. This is a common attitude that social scientists are frequently exposed to. It is my experience that for any given phenomena, multiple contradictory "social science" explanations can be offered. While empirical investigation will usually prove only one of the explanations to be correct, all will be considered common sense.
}

In an earlier review article published in this journal, Beckley and Korber (1995) discussed sociology's past and potential future contributions to forestry. They noted that in the past, social science has made "only minor contributions to forest management and policy." Until recently, economics was the only social science discipline that received

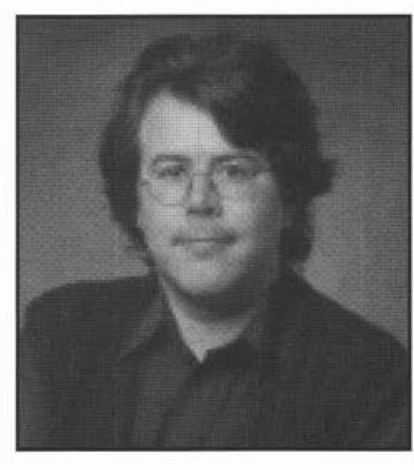
widespread attention by forest managers.

'In the 'old paradigm of forest management' ... economists helped forest managers determine the optimal combination of inputs and maximize financial benefits from a given parcel of forest land. They also assisted with market analyses, labour studies and other financial dimensions of forest management." (Beckley and Korber 1995: 712)

Beckley and Korber (1995) note that as a result of an emerging new paradigm in forestry, there now exists a window of opportunity for social scientists to make a contribution to forestry.

"The emerging forest management paradigm is focused on ecosystem health, the diverse human uses of forests, and long-term sustainability. Such a paradigm will necessarily need to draw on a wider base of scientific research to inform policy." (Beckley and Korber 1995: 712)

Beckley and Korber suggest that social scientists can make contributions by providing data and theoretical insights to forest managers and policy makers. They identify the following as areas in which sociology (in particular) can provide expertise: analyses of stakeholder values, social movements, conflict and its resolution, poverty in forestry-dependent regions, complex organizations, global restructuring, and community stability. 


\section{Current Social Science Inquiry on Forestry Issues: A Survey of Researchers}

As summarized above, Beckley and Korber, in their review of the literature, have identified some potential avenues for social science research on forestry issues. This leads to the question, what is the current state of social science research on forestry issues? In this section I attempt to briefly address this question by summarizing the findings of a recent study of social science research on forest issues in British Columbia.

In the spring of 1996, Elizabeth Bronson conducted a survey of researchers in British Columbia and the surrounding region who were engaged in research on topics related to "society and forestry" (Total N=179). In terms of the distribution of researchers in different areas, the greatest amount of current research is in the following 16 areas:

- Values, attitudes, and perceptions

- Gender issues in forestry and forest communities

- Community-based resource issues

- Sustainable forestry and range management

- Tourism, recreation and leisure

- Biodiversity and ecosystem health

- History of the forests, forestry and forest communities

- Institutional structures and processes

- Planning processes

- Community restructuring

- Decision support

- Economic instruments

- Community forestry

- Forest policy and program evaluation

- Local knowledge (native and non-native)

- Socio-economic impact assessment

\section{Government Support of Social Science Research on Forestry Issues}

Respondents were asked in Bronson's (1996) survey, "Do you think that sufficient consideration is given to social science aspects of forest and range management by the federal, provincial/state and municipal governments, and by the private sectors?" The overwhelming response was "no": federal (78\%), provincial/state (83\%) municipal governments (78\%), and by the private sectors $(89 \%){ }^{3}$

\section{Benefits of Social Science Research on Forestry Issues}

Researchers were asked to list what they saw as the main benefits of increasing the contribution of social science research

\footnotetext{
${ }^{3}$ One of the anonymous referees stated s/he felt that most researchers regardless of discipline - would report that not enough emphasis is being given to his/her discipline. This is undoubtedly true. However, there are some ways in which the challenges faced by social scientists present a special case. First, there are fewer funding opportunities, and some of the opportunities entail constraints on the types of research that is possible. For example, the current CFS/NSERC/SSHRC Forest Research Partnerships Program involves matching funds on the part of the relevant government funding agencies and requires a non-governmental partner. In principle, this type of arrangement biases the type of research that is likely to take place in favor of projects that are connected in some way with timber production - as forest companies are far more likely to be able to provide such funds than are NGOs, and funding is unavailable without a partner. Second, later in this article I will provide some results documenting perceived curriculum gaps in forestry post secondary education at U.B.C. In most instances, gaps in social science curriculum are not merely a gap between the emphasis that social scientists would like to see and what exists, but a gap between the absence of social science curriculum and perceived needs in the curriculum.
}

to forest and range management. About one quarter of respondents referred to "the need to increase understanding of the human side of forestry issues."

"For example, one respondent noted that resource management is primarily about managing peoples' use of forests/range lands, hence we need to understand people. Another posed the question, 'how can effective management be done without also knowing and understanding human motivation for making public change?'” (Bronson 1996: 6)

Other benefits that were frequently mentioned by survey respondents included: "'better' management decisions," "increasing the knowledge base relating to forestry," "reducing conflict," and "empowering communities and stakeholders - providing tools to affected groups."

\section{Facilitating Social Science Research on Forestry Issues}

The respondents in Bronson's survey were asked: "How could the contribution of social science research be increased?" While a variety of responses were observed, $29 \%$ of the sample provided a response corresponding with both of the following categories: (1) by including social sciences in planning and decision-making, and (2) by increasing the funding of social science research. Other frequently observed responses include: "incorporating local values into research," "improving feedback to communities and stakeholders," and "using applied research," "fitting research to social problems." Bronson observes that while many researchers referred to the need for more extension activities (such as "better consultations with community partner"), the survey results indicate that research is most often disseminated through conferences and/or journals.

Researchers were asked to identify what they felt were the key factors which helped or hindered collaboration between social scientists and others involved in research relating to forest and range issues. The most frequently occurring category of responses (35\% of respondents) referred to "opportunities for communication" (e.g., through more inter-disciplinary conferences, workshops, informal discussion, etc.). Bronson notes that there was more consensus regarding the factors that are perceived to hinder collaboration. She notes that "disciplinary bias" (64\%) and "institutional structures" were seen as major impediments (46\%).

Based on her survey results, Bronson identifies five issues that would facilitate social science research on forestry/range issues and increase the contribution made by such research.

These issues include:

- Breaking down institutional and attitudinal barriers

- Increasing collaborative opportunities

- Increasing awareness of the human aspects of forest management

- Increasing funds allocated to social science research

- Increasing networking opportunities

- Increasing extension activities

In sum, Beckley and Korber have identified a number of different ways in which social science has the potential to make important contributions to forestry. Bronson has described the variety of current social science research activities on forestry issues in B.C. and the surrounding region, and has identified some of the challenges faced by forestry social scientists. While some barriers have been faced by social scientists working in this area, social scientists are beginning to meet the demands of forest managers and forest policy makers by bringing their tool kit of theory and methods to bear on forestry problems. While 
Table 1. The relative importance of different areas of knowledge: mail questionnaire - whole sample (n=501). "Responses from the forestry public."

\begin{tabular}{|c|c|c|c|c|c|c|c|c|c|c|}
\hline \multirow[b]{2}{*}{ Area of Knowledge } & \multicolumn{7}{|c|}{ Percent of respondents choosing category } & \multirow[b]{2}{*}{$\operatorname{Mean}^{1}$} & \multirow[b]{2}{*}{ Rank $^{1}$} & \multirow[b]{2}{*}{$\mathbf{N}^{1}$} \\
\hline & $\begin{array}{c}\text { Very } \\
\text { Important } \\
\text { (1) }\end{array}$ & (2) & (3) & (4) & $\begin{array}{c}\text { Unimportant } \\
\text { (5) }\end{array}$ & $\begin{array}{l}\text { Don't } \\
\text { Know }\end{array}$ & $\begin{array}{c}\text { No } \\
\text { Response }\end{array}$ & & & \\
\hline \multicolumn{11}{|l|}{ Humanities/Social Sciences } \\
\hline Conservation ethics & 35.5 & 34.1 & 24.6 & 2.2 & 1.0 & 1.0 & 1.6 & 1.96 & 1 & 488 \\
\hline Economics (micro/macro) & 23.2 & 32.5 & 33.1 & 7.2 & 1.0 & 1.0 & 2.0 & 2.28 & 3 & 486 \\
\hline Indigenous peoples \& Cultures & 10.6 & 24.6 & 42.3 & 14.0 & 5.2 & 1.4 & 2.0 & 2.78 & 7 & 484 \\
\hline Interpersonal relations/ small group dynamics & 29.9 & 35.5 & 23.2 & 7.8 & 1.6 & 0.4 & 1.6 & 2.14 & 2 & 491 \\
\hline Literature \& composition & 13.2 & 28.7 & 31.9 & 16.2 & 6.8 & 0.6 & 2.6 & 2.74 & 6 & 485 \\
\hline Politics/government/ social structure & 9.8 & 26.5 & 34.9 & 19.6 & 6.0 & 0.4 & 2.8 & 2.85 & 8 & 485 \\
\hline Resource community studies & 17.2 & 34.5 & 30.5 & 9.6 & 3.0 & 2.4 & 2.8 & 2.44 & 5 & 475 \\
\hline Social impact assessment & 19.0 & 31.9 & 31.7 & 11.0 & 1.8 & 1.4 & 3.2 & 2.42 & 4 & 478 \\
\hline
\end{tabular}

${ }^{1}$ Mean, Rank, and N (Number) are calculated from the cases for which the question response was 1, 2, 3, 4, or 5 (Very Important through Unimportant) and exclude all cases with the response "Don't Know" or where there was no response.

The Perceived Relevance of Social Science Knowledge

\section{to Forestry Curricula: Some Survey Results}

Above, I have reviewed some trends and issues associated $\dot{\sim}$ with social science research on forestry topics. I will now turn ㅇ to consider the potential for pedagogical contributions to on forestry by social scientists. I will review the results of three surveys I conducted with the "forestry public" (defined Folow), U.B.C. forestry faculty, and U.B.C. undergraduate forestry s students regarding the knowledge and skills that they consider $\dot{0}$ to be "important for the graduating professional forester." Most ZFelevant to the present article are the results for knowledge relat?

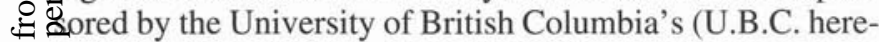
after) Faculty of Forestry, and the B.S.F. (Bachelor of Forestry) Review Task Force. ${ }^{4}$

\section{Methods}

A self-administered questionnaire was developed based on an earlier study undertaken by the U.B.C. Wood Science Department (Cohen and Maness 1995). The new survey instrument was pretested, and revised. The final version of the questionnaire (referred to below as "the mail questionnaire" or the "mail survey") asked respondents to provide information on the relative importance of specific knowledge (e.g., "insects/diseases") and skill items (e.g., "geographic information systems - basics") from two comprehensive lists. People were also asked to evaluate the relative importance of various broad categories of knowledge (e.g., "Humanities/Social Sciences") and skills (e.g., "Field Skills"). Finally, respondents were asked to provide information on the type of organization and sector of the economy they worked in, the type of position they held, their educational background, their familiarity with the UBC Forestry program, their age, and their sex. ${ }^{5}$

${ }^{4} \mathrm{~A}$ similar study was conducted in 1998 by the Pinchot Institute for Conservation. The institute surveyed forestry employers and recent graduates of forestry programs at U.S. colleges and universities (see Sample et al. 1999). The Pinchot Institute survey gave less emphasis to social science curricula in its survey, than did the U.B.C. survey discussed here.

${ }^{5} \mathrm{~A}$ copy of the questionnaire can be obtained by writing the author.

\section{The Mail Questionnaire Sample}

It was the intent of the mail survey study to obtain information from a relatively broad cross-section of people who are knowledgeable and concerned about forestry in B.C. In developing a sampling frame we utilized the mailing list of the B.C. Forestry Continuing Studies Network. We developed a stratified random sample. The following categories were used in stratifying the sampling frame: 1. Professional/Technical People, 2. Forest Management Workers, 3. Harvesting Workers, 4. Environmentalists/Naturalists, 5. Aboriginal Representatives. After eliminating duplicate names, individuals from each of these categories were selected into the sample. The selection procedure employed systematic sampling using a random start. The survey was administered in the spring of 1995. The final sampling frame consisted of 2493 people. We received 507 responses, yielding a response rate of $20.3 \%{ }^{6}$

Respondents were asked to judge what they believed is needed as core knowledge for a professional forester by rating a series of specific knowledge and skill areas. People were asked to rate the items on a scale of 1 (Very Important) to 5 (Unimportant). There were fifty-two specific knowledge items organized under the following seven broad categories: 1) Physical/Biological Sciences, 2) Humanities/Social Sciences, 3) Forest Sciences, 4) Forest Management, 5) Forest Operations, 6) Business/Organizational Management, 7) Public Policy. There were twenty-one skill items organized under the following five broad categories: 1) computer skills, 2) managerial skills, 3) communication skills, 4) field skills, 5) problem solving.

\footnotetext{
${ }^{6}$ This rate is identical to a survey by Cohen and Maness (1995), which was conducted for the purposes of reviewing the wood science program at U.B.C. While this figure is somewhat low by social science standards, it is a good response rate by "market research" standards. From a methodological viewpoint, it is interesting that the "Wood Science" survey and the "Forest Resources Management" survey obtained the same response rate. The "Wood Science" survey employed a non-random sampling procedure, the questionnaire was two pages long, and the survey design did not include a follow-up letter. The "Forest Resources Management" survey used a random-sampling procedure, the questionnaire was four pages long, and the survey design did include a follow-up letter. Thus the response rate of the latter survey was likely reduced somewhat by the length of the questionnaire (it being twice as long as the Wood Science survey questionnaire), but at the same time, the response rate was increased somewhat by the inclusion of a follow-up letter.
} 
Table 2. The relative importance of different areas of knowledge: responses from U.B.C. forestry faculty and U.B.C. forestry students

\begin{tabular}{|c|c|c|c|c|c|c|c|c|}
\hline \multirow{2}{*}{$\begin{array}{l}\text { Area of Knowledge } \\
\text { Humanities/ Social Sciences }\end{array}$} & \multicolumn{4}{|c|}{ Faculty } & \multicolumn{4}{|c|}{ Students } \\
\hline & Now ${ }^{1}$ & Ideal $^{1}$ & Gap Score $^{2}$ & $\mathrm{~N}^{3}$ & Now $^{1}$ & Ideal $^{1}$ & Gap Score $^{2}$ & $\mathrm{~N}^{3}$ \\
\hline Conservation ethics & 3.76 & 2.05 & $1.76^{*}$ & 17 & 3.56 & 2.12 & $1.44 *$ & 43 \\
\hline Economics (micro/macro) & 2.31 & 2.14 & $0.38 *$ & 16 & 2.64 & 2.27 & $0.36 *$ & 44 \\
\hline Indigenous peoples \& cultures & 4.29 & 2.61 & $1.76^{*}$ & 17 & 4.05 & 2.12 & $1.98 *$ & 43 \\
\hline Interpersonal relations/small group dynamics & 3.76 & 1.91 & $1.76^{*}$ & 17 & 3.60 & 1.72 & $1.86^{*}$ & 42 \\
\hline Literature and composition & 3.72 & 2.43 & $1.28 *$ & 18 & 3.60 & 2.74 & $0.86^{*}$ & 42 \\
\hline Politics/Government/Social structure & 3.80 & 2.36 & $1.53^{*}$ & 15 & 3.23 & 1.98 & $1.23^{*}$ & 43 \\
\hline Resource community studies & 4.07 & 2.55 & $1.07 *$ & 14 & 3.80 & 2.44 & $1.33^{*}$ & 43 \\
\hline Social impact assessment & 4.33 & 2.57 & $1.53^{*}$ & 15 & 3.83 & 2.30 & $1.55^{*}$ & 42 \\
\hline
\end{tabular}

\section{Notes:}

${ }^{1}$ The "Now" and "Ideal" scores are mean scores for the Importance Scale where 1 = "Very Important," and 5 = "Unimportant."

${ }^{2}$ The gap score is calculated by subtracting the "Ideal" score from the "Now" score. In some cases there are data only for the "Now" or "Ideal" (due to "Don" know" or "Missing" responses). Such cases are dropped when calculating the "gap score." This table provides all available data for the "Now" and "Ideal" scores (e.g., before cases have been dropped). Thus, the "gap" scores that are listed will sometimes differ from the result that is obtained by hand calculations using the data in the table.

${ }^{3} \mathrm{This}$ is the $\mathrm{N}$ for the cases included to calculate the gap score.

*t-test is significant for "gap" (or difference) score, where p. $\leq .05$.

\section{Results: Mail Questionnaire}

In this section I present the results for the Humanities and Social Sciences questionnaire items from the mail questionnaire (given to the "forestry public" - see Table 1). Of the eight areas listed under the category, Humanities and Social Sciences, only two are currently offered and/or required in the B.S.F. program at UBC; these are: "Economics (micro/macro)," and "Literature and Composition."

Five of the eight items listed were rated below the mid-point (e.g., closer to "Very Important" than "Unimportant"). Of these five, the following four items are not covered (at least as separate courses) in the current program: 1. "Conservation Ethics," 2. "Interpersonal Relations/Small Group Dynamics," 3. "Resource Community Studies," and 4. "Social Impact Assessment."

It should be noted that there were statistically significant intergroup differences in ratings for some of these areas (not shown in Table 1). For example, respondents from NGOs rated the "Indigenous Peoples and Cultures" area of knowledge as being more important $(\bar{x}=2.2)$, compared to respondents from the Private $(\bar{x}=2.9)$ and Public $(\bar{x}=2.8)$ Sectors. Also, younger people were significantly more likely to rate "Indigenous Peoples and Cultures" as being more important $(\bar{x}=2.6$ for "under 35 "; $\bar{x}=2.7$ for "aged 35-44") compared with older people $(\bar{x}=3.0$ for "aged $45-54$ "; $\bar{x}=3.1$ for "aged 55 and older"). Further, women $(\bar{x}=2.4)$ were significantly more likely to rate the "Indigenous Peoples and Culture" item as being important, compared with men $(\bar{x}=2.8){ }^{7}$ As forestry faculty members tend to be a fairly homogeneous demographic group, these results suggest that more attention should be played to the perceived needs of subgroups whose values may differ from those of the average faculty member. ${ }^{8}$

\footnotetext{
${ }^{7}$ One of the anonymous referees noted that the categories used for the intergroup comparisons are different from those used for stratifying the sample. This approach is taken because information about these demographic categories was obtained via the questionnaire but was not available a priori. Thus it was not possible to construct a sampling frame based on the demographic categories. This approach does not present a problem for this part of analysis as the objective is to provide some comparisons between subgroups within the sample, but not to use these subgroups to construct parameter estimates for a larger population.
}

\section{The Faculty/Student Questionnaire}

A slightly altered version of the questionnaire used in the Mail Survey was administered to U.B.C. forestry faculty and students. All forestry faculty received a questionnaire in their mailbox $(\mathrm{N}=42)$. Questionnaires were returned from 21 faculty members, yielding a response rate of $50 \%$ for this component of the study. This questionnaire was also administered to students in a fourth year forestry course. Forty-four students completed the questionnaire (which represented a $100 \%$ response rate, based on those to whom it was administered). Results from these two surveys are presented in Table 2.

The most important difference between the Mail questionnaire and Faculty/Student questionnaire is that the latter asked respondents to rate both the "importance of different knowledge and skill items to the core knowledge of a professional forester," as well as the "importance given in the current professional forester program." The latter question allows the identification of gaps in the (perceived) emphasis given to particular areas of knowledge and skills in the current program, and the emphasis that ideally should be given.

Large positive "gap scores" suggest that knowledge areas and skills should be given more emphasis than they are currently given. Large negative scores suggest that they could be given less emphasis.

\section{Results: Faculty}

Results from faculty revealed that of the eight Humanities/Social Sciences "knowledge areas," seven had a "gap score" $\geq+1.0$. With the exception of "economics (micro/macro)," faculty perceived there to be large gaps between what is currently taught and what should be taught. All of these differences were statistically significant (see Table 2).

\footnotetext{
${ }^{8}$ For example, while the vast majority of forestry faculty members are men. the survey identified a number of statistically significant opinion differences between men and women. Also, while a cross-section of groups identified "Indigenous Peoples and Cultures" as a knowledge area of particular importance, at the time this study was undertaken - to my knowledge - there were no Forestry faculty members in Canada who were Aboriginal. Subsequent to the survey, Peggy Smith has been hired in the School of Forestry at Lakehead University.
} 
not currently part of the forestry curriculum at UBC. Of course, there is a question regarding the generalizability of these results. On purely statistical grounds, these results can not be generalized beyond the populations from which samples were drawn. On the other hand, it should be noted that the UBC Faculty of Forestry is one of the largest and most influential in North America. It provides training to a relatively high proportion of professional foresters in B.C. and Canada. While there are some variations in the curricula of different forestry schools and in the problems faced by professional foresters in different regions, it would be surprising if many of the observations made above were not applicable to other schools and regions.

The problem of interdisciplinarity was raised in both written responses to the questionnaires and by one of the anonymous referees of this article. Survey results suggest that interdisciplinary approaches need to be given more emphasis in forestry curricula. This is a topic worthy of article-length consideration, and I will only touch upon a couple of issues here.

When foresters, students, and others call for a more interdisciplinary approach they are often calling for the incorporation of social science knowledge into the solution of forestry problems. One solution often proposed by my colleagues is to offer upper level courses where "multiple values" and "multiple approaches" are integrated. I believe this is a worthy goal. However, a serious difficulty exists with this proposed solution - as the analysis of curriculum gaps suggests because students do not have prior exposure to "social science basics." Thus, in upper level courses that attempt to integrate multiple values into planning and policy, students are being asked to integrate knowledge they have learned in biology, ecology, forest operations, forest measurement, etc. with social science knowledge - that they have not obtained during the course of their studies. In my opinion, more exposure to social science in earlier years of undergraduate programs is necessary for integration of values/approaches to successfully be achieved in upper level courses.

A second problem, is that much - if not most - interdisciplinary research is really multi-disciplinary research. In my experience, many interdisciplinary research projects are really multi-disciplinary is the sense that they bring researchers together from different disciplines to work on their own pet projects as part of a larger multi-disciplinary undertaking organized around a broad natural resource topic. Until researchers - especially academic researchers - are able to integrate different disciplinary approaches to work on integrated natural resource management problems it may be too much to ask students to do this. Then again, perhaps we could learn from our students' efforts in this regard.

In this article I have tried to document the perceived need for more social science content in forestry curricula. Of course, there are ever increasing demands on faculty and students in terms of new material. While there was support fron a cross-section of survey respondents for more emphasis or social science, this does not mean that less emphasis shouk be given to core natural science knowledge areas, or to the tech nical skills needed by professional foresters. The demand fo. a greater breadth of knowledge poses challenges to aca demics in revising and developing curricula. In face o increasing and competing demands there is sometimes an impuls to develop "simplifying and streamlining" strategies. Alon these lines some critics have suggested that emphasis tc "peripheral material" such as social science could be droppec or given token coverage in the curricula. I would suggest tha these types of "solutions" should be resisted. In thinkin about foresters - especially foresters of the future - there i: a tendency to create an "ideal type" of the "operationa forester." When we focus on such an ideal type, emphasis ir forestry curricula is given primarily to technical skills. Whils I would again reiterate that technical competence is crucial many if not most forestry graduates will not end up as oper ational foresters. Forestry graduates are distributed amongs the private, public, and not-for profit sectors - nearly a: many work for the public as the private sector. Many forestry graduates end up working in policy and communication posi. tions, and many will become involved in public land planning processes at some point in their career. While social scienct curricula may also be valuable to operational foresters, it is nec. essary to the education of foresters in other roles who need tc interact with the public, and who need to take public concerns values, and opinions into consideration in helping to manag forest lands.

\section{Acknowledgements}

I would like to thank the other members of the BSF Curriulum Task Force for their contributions to the develop. ment of the survey instrument: Gordon Baskerville, Phi Burton, Peter Marshall, John Nelson, and Bart van der Kamp I would also like to thank Chantelle Marlor for her assistance with the data analysis.

\section{References}

Beckley, T. and D. Korber. 1995. Sociology's potential to improvt forest management and inform forest policy. For. Chron. 71: $712-719$ Bronson, E. 1996. Summary Report. Society and Forestry: A Directory of Researchers in British Columbia and the U.S. Pacific Northwest. British Columbia Ministry of Forests Research Branch Victoria, B.C.

Cohen, D.H. and T. Maness. 1995. Educational Needs of the Canadian Solid Wood Products Industry. Wood and Fiber Science 27: 126-133.

Marchak, M.P. 1983. Green Gold: The Forest Industry in Britist Columbia. U.B.C. Press, Vancouver, B.C.

Sample, V.A., P.C. Ringgold, N.E. Block and J.W. Giltmier 1999. Forestry Education: Adapting to the Changing Demands on Professionals. J. For. 97 (9): 4-10. 